\title{
Cross-linguistic representations of numerals and number marking*
}

\author{
Alan Bale \\ Concordia University \\ Michaël Gagnon \\ University of Maryland \\ Hrayr Khanjian \\ Massachusetts Institute of Technology
}

\begin{abstract}
Inspired by Partee (2010), this paper defends a broad thesis that all modifiers, including numeral modifiers, are restrictive in the sense that they can only restrict the denotation of the NP or VP they modify. However, the paper concentrates more narrowly on numeral modification, demonstrating that the evidence that motivated Ionin \& Matushansky (2006) to assign non-restrictive, privative interpretations to numerals - assigning them functions that map singular sets to sets containing groups - is in fact consistent with restrictive modification. Ionin \& Matushansky's (2006) argument for this type of interpretation is partly based on the distribution of Turkish numerals which exclusively combine with singular bare nouns. Section 2 demonstrates that Turkish singular bare nouns are not semantically singular, but rather are unspecified for number. Western Armenian has similar characteristics. Building on some of the observations in section 2, section 3 demonstrates that restrictive modification can account for three different types of languages with respect to the distribution of numerals and plural nouns: (i) languages where numerals exclusively combine with plural nouns (e.g., English), (ii) languages where they exclusively combine with singular bare nouns (e.g., Turkish), (iii) languages where they optionally combine with either type of noun (e.g., Western Armenian). Accounting for these differences crucially involves making a distinction between two kinds of restrictive modification among the numerals: subsective vs. intersective modification. Section 3 also discusses why privative interpretations of numerals have trouble accounting for these different language types.
\end{abstract}

Keywords: numeral modifiers, plural, singular, general number, restrictive modification, subsective modification, intersective modification, privative modification, Turkish, Western Armenian

* We would like to thank Brendan Gillon, Bernhard Schwarz and three anonymous reviewers for comments on this research. We would also like to thank the organizers and participants at SALT 2010.

○2011 A. Bale, M. Gagnon, \& H. Khanjian 
Cross-linguistic representations of numerals and number marking

\section{Introduction}

Numerals such as one, two and three have traditionally been treated either as generalized quantifiers (Montague 1974; Barwise \& Cooper 1981) or restrictive modifiers (Link 1983). In fact, their status as generalized quantifiers can be derived from their modifier interpretation either through a covert existential quantifier (Link 1983), existential closure (Heim 1982; Winter 1997, 2001) or type-shifting (Partee 1986; Landman 2003). More recently, Ionin \& Matushansky (2006) have proposed, contrary to Link (1983), that numerals are not restrictive modifiers. Rather they map sets of singularities to sets of pluralities. As a result, the denotation of the modified NP is disjoint from the denotation of the original NP. This characteristic is very similar to privative adjectival modifiers like fake (Kamp \& Partee 1995; Partee 1995, 2010; Chierchia \& McConnell-Ginet 2000). For example, intuitively, the denotation of fake gun seems to be disjoint from the denotation of gun - no gun is a fake gun. However, Partee (2010) attempts to defend a very strong thesis that all adjectival modifiers are restrictive and hence that there are no true privative adjectives. ${ }^{1}$

In this paper, we defend Link's (1983) original thesis that numerals are restrictive modifiers. However, this defence should be understood as but a small component of an even stronger position than the one proposed by Partee (2010), a position that maintains that all modifiers - including all adjectival, adverbial and numeral modifiers - are restrictive. In other words, the denotation of a modified NP or VP should always be a subset of the original NP or VP. We will call this hypothesis the Strong Thesis.

There are many empirical challenges to the Strong Thesis, including the privative and other non-subsective adjectives discussed by Partee (2010). However, in what follows we limit our attention to one of the motivating pieces of evidence for Ionin \& Matushansky's (2006) interpretation of numerals. ${ }^{2}$ In many languages with a surface singular-plural distinction, numeral modifiers combine with singular (bare) nouns and yield a set of pluralities. One such language is Turkish, as shown in (1).

(1) TURKISH

a. iki çocuk

two boy

"two boys"

1 According to Partee (2010), the surface characteristics of fake can be explained by the interaction of certain grammatical and pragmatic mechanisms. Part of her defence involves a coherent analysis of sentences like This gun is fake.

2 For space reasons, we will not address one of the other motivating pieces of evidence, namely the composition of complex numerals such as two hundred. However, we believe that this piece of evidence is consistent with restrictive modification as well, so long as hundred is not treated as a modifier. 


\section{b. * iki çocuk-lar two boy-PL}

In Turkish, nouns can either appear with the plural morpheme -lar or without. However, as demonstrated in (1b) the plural morpheme is not permitted when a noun is modified by a numeral like iki ('two'). If the meaning of the noun çocuk were the set of singular male children (similar to the meaning of boy in English) and if the meaning of iki çocuk were the set of pairs of male children (similar to two boys in English), then the numeral modifier $i k i$ would not be a restrictor. The modified NP would not contain any of the original members of the singular noun.

Based partly on the Turkish data, Ionin \& Matushansky (2006) assign a privative interpretation to $i k i$ similar to the one in (2).

$$
\llbracket i k i \rrbracket=\lambda P_{s g} \cdot\left\{x: \exists Y\left(Y \in \operatorname{PART}(x) \&(|Y|=2) \& \forall z\left(z \in Y \rightarrow z \in P_{s g}\right)\right)\right\}
$$

a. A predicate $Q$ is of type $P_{s g}$ iff $\forall x, y \in Q(x \ngtr y \& y \ngtr x)$

b. $\operatorname{PART}(x)=\operatorname{def}_{\text {d }}\{Z: Z \text { is a partition of } x\}^{3}$

According to (2), $\llbracket i k i \rrbracket$ is a function from a set $Q$ that contains no sub-aggregates (subgroups) or super-aggregates (supergroups) to a set $P$ that contains only pairs, each member of the pair being an original member of $Q$. For example, if $\llbracket i k i \rrbracket$ combined with the set $\{a, b, c\}$, perhaps the set of single boys, the result would be the set $\{a b, a c, b c\}$, the set of all possible pairings of boys (see (3)).

$$
\llbracket i k i \rrbracket(\{a, b, c\})=\{a b, a c, b c\}
$$

The set $\{a, b, c\}$ is disjoint from $\{a b, a c, b c\}$. If the Strong Thesis has any hope of being right, then the semantics in (2) cannot possibly be correct. Modifiers should only be able to restrict denotations.

As demonstrated above, a crucial part of Ionin \& Matushansky's motivation for a privative semantics rests on the assumption that bare nouns like çocuk are semantically singular. However, as discussed in Corbett 2000, there are several languages that have a bare-noun/plural-noun contrast where the bare noun is not semantically singular but rather is unspecified for number (Corbett (2000) labelled this general number; see also Kang 1994; Wilhelm 2008, 2006). A prediction of the Strong Thesis is that languages which permit numerals to combine with bare-nouns are languages where the bare noun is unspecified for number. In this way, numerals like $i k i$ could still be interpreted as restrictors. As demonstrated in section 2, this prediction holds for at least two such languages: Turkish and Western Armenian.

3 A partition of an aggregate $x$ is a set of aggregates $Z$ such that the join (sum) of all the elements in $Z$ is equal to $x(\bigvee Z=x)$ and for any two elements, $w$ and $v$, in $Z$, the meet of those two elements is empty $(w \wedge v=\emptyset)$ 
Another interesting data point that is consistent with the strong thesis involves the distinction between two types of restrictive modification - subsective vs. intersective (Kamp \& Partee 1995; Partee 1995, 2010; Chierchia \& McConnell-Ginet 2000). The adjective pregnant is a prototypical intersective modifier. To determine the interpretation of the NP pregnant mouse, it is sufficient to intersect the set of all the things that are pregnant with the set of all the mice. In other words, pregnant can be interpreted as a set and restrictive modification can be achieved through intersection. In contrast, the adjective big - a prototypical subsective modifier - cannot be straightforwardly assigned a set interpretation. To understand why, consider the two NPs big mouse and big animal. Suppose that Fred is an eight inch

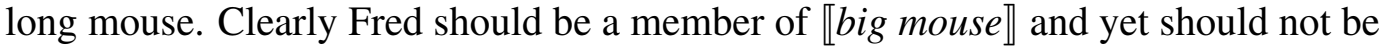

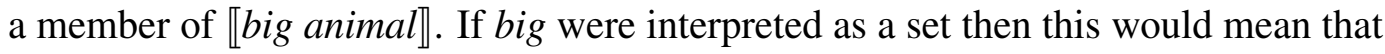

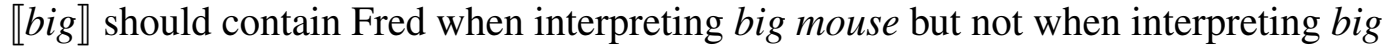
animal. Subsective adjectives like big have a relative interpretation; how they affect the noun depends on the nature of the noun that they modify. Yet such adjectives still

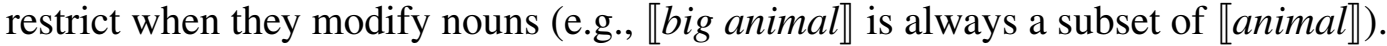

Although the Strong Thesis rules out the possibility of privative and other non-restrictive modification, it still permits a distinction between intersective and subsective modification. In fact, given the adjectival data, such a distinction for numerals should be likely. As demonstrated in section 3, not only are intersective and subsective numerals consistent with the crosslinguistic data, they also account for different types of languages with respect to numerals and plural marking.

Crosslinguistically, there are at least three ways that a given language combines nouns with plural markers and numerals. There are languages like English where numerals greater than one obligatorily combine with plural nouns, there are languages like Turkish where such numerals obligatorily combine with bare nouns, and finally there are languages like Western Armenian where such numerals optionally combine with either bare nouns or plural nouns. Assuming that the Strong Thesis is correct, any language where the bare noun is semantically singular will be a language where numerals greater than one obligatorily combine with plural nouns. In contrast, there are two options for languages where the bare noun is unspecified for number. If numeral modifiers are subsective, then such numerals will obligatorily combine with bare nouns (Turkish). If they are intersective, then they could optionally combine with either type of noun (Western Armenian).

\section{General Number}

As shown in (4) and (5), both Turkish and Western Armenian permit numerals greater than one to combine with bare nouns, despite the fact that both of these languages have a productive plural morpheme (-lar in Turkish, -(n)er in Western 
Armenian). This characteristic, as shown in (6), is completely distinct from English.

(4) TURKISH

a. çocuk boy

b. çocuk-lar boy-PL

c. iki çocuk

two boy

(5) WESTERN ARMENiAn

a. dəgha

boy

b. dəgha-ner

boy-PL

c. yergu dəgha

two boy

(6) ENGLISH
a. boy
b. boy-s
c. * two boy

If the Strong Thesis is correct, then bare nouns in Turkish and Western Armenian should not be semantically singular as they are in English. The behaviour of singular nouns in predicate position supports this prediction (cf., Donabédian 1993; Schroeder 1999; Borer 2005). Consider the sentences in (7) and (8).

(7) TURKISH

a. John çocuk

John boy

'John is a boy'

b. John ve Brad çocuk

John and Brad boy

'John and Brad are boys'

(8) WeStERn ARMENiAn

a. John-ə dəgha e

John-def boy is

'John is a boy' 
Cross-linguistic representations of numerals and number marking

\section{b. John-ə yev Brad-ə dəgha en \\ John-def and Brad-def boy are \\ 'John and Brad are boys'}

When appearing in predicate position, the nouns çocuk and dəgha can serve as predicates to both singular subjects such as proper names (7a and 8a) and plural subjects such as conjoined NPs (7b and 8b). ${ }^{4}$ As discussed in Kang 1994, Korean has similar properties.

This distribution contrasts sharply with English, where the bare noun can only be predicated coherently of singular subjects. Consider the difference in coherency between (9a) and (9b).

\section{(9) ENGLISH}
a. John is a boy.
b. ?? John and Brad are a boy.

In contrast to (9a), the sentence in (9b) is extremely awkward. Note, however, that this awkwardness does not stem from a number mismatch between the subject and predicate. As shown in (10), singular predicates can appear with plural subjects when the predicate is a singular mass noun or a group denoting count noun.

\section{ENGLISH}

a. That chair and table are furniture.

b. John and Brad are an interesting couple.

Furthermore, (9b) even has a coherent interpretation if it is somehow understood to mean that John and Brad together make up a boy - perhaps under a conjoined-twin or costume interpretation similar to (11).

(11) John and Brad each occupy one half of the costume. Together, they are a horse.

The source of awkwardness in (9b) is semantic in nature - the sentence cannot mean that both John and Brad are boys.

This contrast in distribution demonstrates that the Turkish and Western Armenian nominal predicates, çocuk and dəgha, have a broader applicability than their English counterpart: they are true of both groups and singulars whereas boy is only true of singulars. This difference can be explained if the Turkish and Western Armenian predicates have a more inclusive denotation than the English predicate. For example,

4 The judgments do not change if plural NPs are used. However, since the meanings of plural versus singular are at issue here, we refrained from using plural NPs in our examples. 
suppose that bare nouns only denote a set of singular individuals in English whereas in Turkish and Western Armenian bare nouns denote a set not only containing all the singular individuals but also any groups/aggregates that can be formed from those individuals. ${ }^{5}$ The proposed semantic difference can be represented by the denotations in (12).

(12) In a context where the boys are $a, b$ and $c$.

a. $\llbracket d ə g h a \rrbracket=\llbracket c ̧ o c u k \rrbracket=\{a, b, c, a b, a c, b c, a b c\}$

b. $\llbracket b o y \rrbracket=\{a, b, c\}$

With this kind of interpretation, it would be expected that Turkish and Western Armenian bare nouns could be predicated of groups whereas English bare nouns could not. Furthermore, with this type of denotation, the modifiers iki and yergu would be restrictive and hence consistent with the Strong Thesis. They would apply to a very broad denotation containing groups of all sizes and restrict the denotation to groups of two.

(13) In a context where the boys are $a, b$ and $c$.

a. $\llbracket d \partial g h a \rrbracket=\llbracket c ̧ o c u k \rrbracket=\{a, b, c, a b, a c, b c, a b c\}$

b. $\llbracket$ yergu dəgha $\rrbracket=\llbracket y e r g u \rrbracket(\{a, b, c, a b, a c, b c, a b c\})=\{a b, a c, b c\}$

c. $\llbracket i k i$ çocuk $\rrbracket=\llbracket i k i \rrbracket(\{a, b, c, a b, a c, b c, a b c\})=\{a b, a c, b c\}$

The explicit interpretation of these modifiers will be left to section 3 where we explore some differences between Turkish and Western Armenian.

If this characterization is correct, then it is an interesting question to ask what role (if any) plural morphemes play in Turkish and Western Armenian. In English, the plural morpheme's role is obvious - count nouns cannot be predicated of groups unless they are augmented by the plural morpheme. In Turkish and Western Armenian, the plural morphemes do not augment the interpretation of the bare noun, but rather they restrict it. For example, consider the sentences with plural nouns in (14) and (15).

\section{TURKISH}

5 Another possibility would be that Turkish and Western Armenian allow the subjects to distribute over nominal predicates whereas English does not. We do not rule out this possibility in this paper, rather we merely show that predicate distribution is consistent with the thesis that the bare nouns are underspecified for number. However, it should be noted that there is no independent support for a difference of distribution between the three languages. Furthermore, there is independent support in Western Armenian that bare nouns are underspecified for number. Such support involves indefinite expressions and derived kind interpretations (see Bale \& Khanjian 2009, Bale, Gagnon \& Khanjian 2010). 
Cross-linguistic representations of numerals and number marking

a. John ve Brad çocuk-lar

John and Brad boy-PL

'John and Brad are boys'

b. * John çocuk-lar

John boy-PL

(15)

WESTERN ARMENIAN

a. John-ə yev Brad-ə dəgha-ner en John-def and Brad-def boy-PL are

'John and Brad are boys'

b. *John-ə dəgha-ner e John-def boy-PL is

As shown in (14a) and (15a), plural nouns in Turkish and Western Armenian coherently apply to group-denoting subjects, however as shown in (14b) and (15b), they cannot be predicated of singular subjects. This evidence suggests that the denotation of plural nouns in these languages only contain groups and do not contain any singular individuals. ${ }^{6}$

(16) In a context where the boys are $a, b$ and $c$.

a. $\llbracket d \partial g h a \rrbracket=\llbracket c ̧ o c u k \rrbracket=\{a, b, c, a b, a c, b c, a b c\}$

b. $\llbracket$ dəgha-ner $\rrbracket=\llbracket c ̧ o c u k$-lar $\rrbracket=\{a b, a c, b c, a b c\}$

The lack of singular individuals in the plural denotation will become relevant for our discussions in section 3 concerning intersective and subsective modification.

\section{Intersective and Subsective Modification}

Although the Strong Thesis rules out privative modification, it does permit different types of restrictive modification. There are at least two types of restrictive modifiers discussed in the literature on adjectives: intersective and subsective. As we demonstrate in this section, it might be beneficial to analyze numeral modification in a similar vein, hypothesizing both intersective and subsective modification. In fact, such a distinction, in combination with the Strong Thesis, predicts three different types of languages regarding the interaction between numerals and plurality:

i. Languages where numerals greater than one obligatorily combine with plural nouns;

6 Consistent with this data point is the fact that existential plural DPs in Western Armenian cannot refer to or quantify over singular individual in downward entailing contexts (see Bale \& Khanjian 2009; Bale et al. 2010). 
ii. Languages where such numerals obligatorily combine with bare nouns;

iii. Languages where such numerals optionally combine with plural nouns or bare nouns.

In sections 3.1 to 3.3, the three types of languages are represented by English, Turkish and Western Armenian respectively.

\subsection{English (Obligatory Plural)}

As was demonstrated in (6), repeated in (17), English requires plural marking when nouns combine with numerals greater than one.

(17) ENGLISH

(Obligatory Plural)
a. * two boy
b. two boys

Given the Strong Thesis, this result is unsurprising. (Although it would be completely surprising if numeral modifiers were privative as suggested by Ionin \& Matushansky 2006.) As demonstrated in section 2, English bare nouns are semantically singular: they contain no super-aggregates (groups larger than one). If numerals are restrictive modifiers and the result of restricting a noun by a modifier like two is a denotation containing groups of two, then such numerals would require non-singular denotations - denotations which are closed under the sum operator. In English, only plural nouns are closed under the sum operator (cf. Link 1983).

\subsection{Turkish (Obligatory Singular)}

In contrast to English are languages like Turkish where numerals greater than one obligatorily combine with bare nouns. This was demonstrated by (1) above, repeated in (18).

\section{(18) TURKISH}

(Obligatory Singular)
a. iki çocuk
two boy(sg)
'two boys'
b. * iki çocuk-lar two boy-PL 
Cross-linguistic representations of numerals and number marking

This pattern can be explained if numeral modifiers have a subsective interpretation. The explanation, however, relies on a characterization of Turkish such as the one presented in section 2 where bare nouns denote the set of all singular individuals as well as any group formed from these individuals. In contrast, plural nouns only denote the groups (see (16a) compared to (16b), repeated in (19)).

(19) In a context where the boys are $a, b$ and $c$.

a. $\llbracket c ̧ o c u k \rrbracket=\{a, b, c, a b, a c, b c, a b c\}$

b. $\llbracket c$ cocuk-lar $\rrbracket=\{a b, a c, b c, a b c\}$

In the literature, there are already several proposals of numeral interpretations that involve subsective modification (motivated by the semantics of count-mass syntax, partitive constructions and measure phrases). Such proposals often relativize measurement (counting groups) to the noun being modified (cf., Bale et al. 2010; Bale \& Barner 2009; Bale 2009; Magri 2008). In such proposals, numerals such as two (or iki) restrict denotations to groups containing two individuals, but what counts as an individual depends on the nominal complement. Intensionally, these interpretations define an individual as a minimal part in the nominal denotation. Thus, what extensionally counts as an individual changes from denotation to denotation. This is very similar to how gradable adjectives like big change their meaning depending on their nominal complement (see Klein 1980, 1982; Kennedy 2007 and references therein) - what counts as big is different when considering big elephants vs. big mice. $^{7}$

An example of a possible subsective interpretation of $i k i$ is given in (20) with some relevant definitions provided in (21).

SUBSECTIVE NUMERAL MODIFICATION

a. $\llbracket i k i \rrbracket=\lambda P_{p l} \cdot\left\{x: x \in P_{p l} \& \exists Y\left(Y \in \operatorname{PART}(x) \&|Y|=2 \& \forall z\left(z \in Y \rightarrow z \in \operatorname{MIN}\left(P_{p l}\right)\right)\right)\right\}$

\section{SOME DEFINITIONS}

a. A predicate $Q$ is of type $P_{p l}$ iff $\forall x, y \in Q(x \oplus y \in Q)$

b. $\operatorname{MIN}(P)$ is defined iff

$\forall x, y((x, y \in P \& \neg \exists z(z \in P \&(z<y \vee z<x))) \rightarrow x \wedge y=0)$.

When defined $\operatorname{MIN}(P)=\{x: x \in P \& \neg \exists z(z<x)\}$.

According to (20), the interpretation of $i k i$ is a function from denotations that are closed under the sum operator (see definition $(21 \mathrm{a}))^{8}$ to one of their subsets, namely

7 Hence why, like gradable adjectives, we call this type of modifier subsective: it restricts the nominal complement but it cannot be assigned a denotation independent of its nominal complement.

8 The criterion that the function only applies to denotations closed under the sum operator prevents vacuous application of the numeral to singular denotations. 
the subset that consists of all and only the groups that are composed of two nonoverlapping minimal parts (atomic minimal parts). As specified in the left side of the implication in the last conjunct of (20), an atomic minimal part is determined by applying the MIN function to a nominal predicate. According to the definition in (21b), an atomic minimal part in a given nominal predicate is the smallest possible aggregate that does not share any parts with other members of the predicate. Note that the criterion that the smallest aggregates in the predicate do not share parts (do not overlap) is introduced as a presupposition.

With this interpretation of $i k i$, let us consider how such a numeral modifier could apply to the Turkish bare noun and plural noun. With respect to bare nouns, the numeral restricts the noun yielding the correct interpretation: a set of possible pairs.

(22) In a context where the boys are $a, b$ and $c$.

a. $\llbracket c o c u k \rrbracket=\{a, b, c, a b, a c, b c, a b c\}$

b. $\llbracket i k i \rrbracket(\llbracket c o c u k \rrbracket)=\llbracket i k i \rrbracket(\{a, b, c, a b, a c, b c, a b c\})=\{a b, a c, b c\}$

The result is defined since the denotation of the bare noun has non-overlapping minimal parts that serve as the basis for counting, namely $a, b$ and $c$. Thus, the group ac belongs to the restricted denotation since it consists of two non-overlapping minimal parts (a.k.a., individuals). Similar reasoning holds for $a b$ and $c b$.

With respect to plural nouns, the situation is quite different. Since the application of $\llbracket i k i \rrbracket$ to a noun requires that the noun have non-overlapping minimal parts, $\llbracket i k i \rrbracket$ cannot be applied to plural nouns (the result is undefined).

(23) In a context where the boys are $a, b$ and $c$.

a. $\llbracket$ çocuk-lar $\rrbracket=\{a b, a c, b c, a b c\}$

b. $\# \llbracket i k i \rrbracket(\llbracket c o c u k \rrbracket)=\llbracket i k i \rrbracket(\{a b, a c, b c, a b c\})=$ undefined

Although such nouns do have minimal parts $-a b, a c$ and $b c$ are the smallest aggregates in the denotation - the minimal parts overlap $(a b \wedge a c=\mathrm{a}, a b \wedge b c=\mathrm{b}, a c \wedge b c$ $=c)$. Thus, there are no individuals to serve as a basis for counting. A subsective interpretation of numerals like $i k i$ predicts that they will be able to combine with bare nouns but not plural nouns.

\subsection{Western Armenian (Optional Marking)}

Although the semantic interpretation of bare nouns and plural nouns in Western Armenian is identical to Turkish (see section 2), the distribution of numerals is slightly different (see Donabédian 1993; Borer 2005; Bale \& Khanjian 2009). Consider the phrases in (24). 
Cross-linguistic representations of numerals and number marking

WESTERN ARMENIAN

(Optional Marking)

a. yergu dəgha

two boy(sg)

'two boys'

b. yergu dəgha-ner

two boy-PL

'two boys'

Unlike Turkish, the numeral meaning two (yergu) can combine with both bare nouns and plural nouns. Such flexibility would be impossible if Western Armenian modifiers were subsective like they are in Turkish. However, such a distribution would follow naturally if such numerals were interpreted as a type of intersective modifier.

The earliest proposals of numeral modification (such as Link 1983) provide a semantics where counting is determined by the overall model and is not relativized to a nominal denotation (see also Chierchia 1998). In fact, this is often implicitly assumed in any modifier semantics that employs a set or group cardinality operator. In such a semantics, it is possible - although not necessary - to assign numerals a denotation separate from the nominal. For the sake of exposition, we will provide such an interpretation to highlight the intersective nature of the numeral modifiers. Consider the possible interpretation of yergu in (25a) along with the definition of ATOM in (25b) .

INTERSECTIVE NUMERAL INTERPRETATION

a. $\llbracket$ yergu $\rrbracket=\{x: \exists Y(Y \in \operatorname{PART}(x) \&|Y|=2 \& \forall z(z \in Y \rightarrow \operatorname{ATOM}(z)))\}$

b. $\operatorname{ATOM}(x)=1$ iff $x$ is an atom in the domain of the model - iff $x \in D \& \neg \exists z \in$ D. $(z<x)$

If the method of counting (the atoms) is determined by the model (as specified in (25b)), then yergu can be interpreted as the set of all groups/aggregates consisting of two atoms (as specified in (25a)). ${ }^{9}$ Modification of a bare noun can be achieved through intersection, as demonstrated in (26). ${ }^{10}$

9 This type of interpretation makes accounting for complex numerals more complicated, however such complexities can be overcome by permitting sets of higher types. See Link 1983 and Landman 1989 for a discussion.

10 To keep a consistency in the type assignment for modification, it is desirable to assign the following function as the interpretation of yergu. $\llbracket y e r g u \rrbracket=\lambda P_{p l} . P_{p l} \cap\{x: \exists Y(Y \in \operatorname{PART}(x) \&|Y|=2 \& \forall z(z \in Y \rightarrow \operatorname{ATOM}(z)))\}$ 
(26) In a context where the atoms consist of the individual boys ( $a, b$ and $c$ ), a girl

(e) and a chair $(f)$.

a. $\llbracket y e r g u \rrbracket=\{a b, a c, a e, a f, b c, b e, b f, c e, c f, e f\}$

b. $\llbracket d \partial g h a \rrbracket=\{a, b, c, a b, a c, b c, a b c\}$

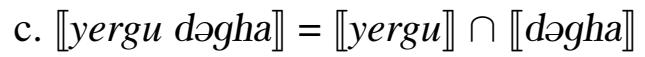

$=\{a b, a c, a e, a f, b c, b e, b f, c e, c f, e f\} \cap\{a, b, c, a b, a c, b c, a b c\}$

$=\{a b, a c, b c\}$

The result of intersecting the set of all groups of two atoms with the set of all possible groups of boys is the set of groups of two boys. Note that this kind of modification has no requirement that the nominal denotation contain non-overlapping minimal parts. Thus, yergu can modify a plural noun in the same way that it can modify a bare noun - compare (26) to (27).

(27) In a context where the atoms consist of the individual boys ( $a, b$ and $c$ ), a girl (e) and a chair $(f)$.

a. $\llbracket y e r g u \rrbracket=\{a b, a c, a e, a f, b c, b e, b f, c e, c f, e f\}$

b. $\llbracket d \partial g h a-n e r \rrbracket=\{a b, a c, b c, a b c\}$

c. 【yergu dəgha-ner $\rrbracket=\llbracket y e r g u \rrbracket \cap \llbracket$ dəgha-ner $\rrbracket$ $=\{a b, a c, a e, a f, b c, b e, b f, c e, c f, e f\} \cap\{a b, a c, b c, a b c\}$ $=\{a b, a c, b c\}$

As a result of intersective modification, Western Armenian numerals have a greater flexibility than Turkish numerals.

\subsection{Summary}

As shown in this section, the Strong Thesis along with a distinction between intersective and subsective modification, can account for three types of languages: one where numerals obligatorily combine with plural nouns, another where they obligatorily combine with bare nouns and a third where they optionally combine with either. The first type, with obligatory plurals, follows directly from the Strong Thesis. If bare nouns are semantically singular (as they are in English), then restrictive modifiers like two would require plural nouns. The second type, with obligatory singulars, also follows from the Strong Thesis but in combination with the hypotheses that numerals are subsective modifiers and bare nouns are unspecified for number. The subsective modifier requires the broad, underspecified denotation of the bare nouns. The third type, with optional plurals, also follows from the hypothesis that bare nouns are unspecified for number, but with the additional hypothesis that the numerals are intersective modifiers. The intersective modifiers only require that 
nominal denotations be closed under the sum operator. Both bare nouns and plural nouns have this property.

These three types of languages do not necessarily exhaust the different types of languages that are consistent with the Strong Thesis. It is possible that some languages will have a mix of intersective and subsective numeral modifiers just as they do for adjectives. It is also possible that languages will have more than one type of plural and more than one type of bare noun. ${ }^{11}$ It remains an open question (and a future research project) whether such intricacies can account for more complex languages such as Russian and Hungarian.

\section{Conclusion}

This paper advanced the strong thesis that all modifiers are restrictive. It is strong in the sense that it is easily falsifiable. It would be surprising if data, which on the surface seemed to contradict the Strong Thesis, turned out to be consistent under closer examination. Partee (2010) has shown this to be the case with respect to privative adjectives. In this paper, we have attempted to show this with respect to privative numeral modifiers. In fact, we have attempted to go one step further. As demonstrated in section 3, the Strong Thesis provides a better account of why so many languages require plural marking when combining nouns with numerals greater than one.

It would be remarkable if every language that permits numerals to combine with bare nouns has the same semantic characteristics as Turkish and Armenian: bare nouns being unspecified for number; plural nouns specified for plurality. It would be equally remarkable if there is a strong correlation between optionality and intersective vs. subsective numeral modification. These results would be completely unexpected if the Strong Thesis were incorrect.

This paper is but the beginning of a long term research project that includes languages like Korean, Russian, Finnish and Hungarian. ${ }^{12}$ It remains an open question whether there are languages that have numerals that combine with semantically singular bare nouns. It also remains open whether the differences between subsective and intersective modification can be independently confirmed by other properties of the grammar. Further research will hopefully answer some of these questions.

11 In fact, languages with a mass-count distinction demonstrate that there is more than one type of bare noun. However, there are no plural operators that can apply to the mass type.

12 As discussed in Kang 1994, Korean has the semantic characteristics of Turkish and Armenian but does not permit numerals to combine with bare nouns. As discussed in Ionin \& Matushansky 2006, Russian has a complex and idiosyncratic interaction between numerals, plurality and case marking. Preliminary research on Finnish suggests that its bare nouns are unspecified for number much like Turkish and Armenian and hence why it too allows numerals to combine with bare nouns. 


\section{References}

Bale, Alan. 2009. Yet more evidence for the emptiness of plurality. In Proceedings of the Northeast Linguistics Society NELS 38, 75-88. University of Massachussetts: Graduate Linguistic Students' Association, Umass.

Bale, Alan \& David Barner. 2009. The interpretation of functional heads: Using comparatives to explore the mass/count distinction. Journal of Semantics 26. 217-252. doi:10.1093/jos/ffp003.

Bale, Alan, Michaël Gagnon \& Hrayr Khanjian. 2010. On the relationship between morphological and semantic markedness: the case of plural morphology. Morphology doi:10.1007/s11525-010-9158-1.

Bale, Alan \& Hrayr Khanjian. 2009. Classifiers and number marking. In Effi Georgala \& Jonathan Howell (eds.), Proceedings of Semantics and Linguistic Theory SALT XVIII, Cornell University, Ithaca, NY: CLC Publications.

Barwise, John \& Robin Cooper. 1981. Generalized quantifiers and natural language. Linguistics and Philosophy 4. 159-219. doi:10.1007/BF00350139.

Borer, Hagit. 2005. Structuring sense. Oxford: Oxford University Press.

Chierchia, Gennaro. 1998. Plurality of mass nouns and the notion of "semantic parameter". In Susan Rothstein (ed.), Events and grammar, 53-104. Kluwer Academic Publishers.

Chierchia, Gennaro \& Sally McConnell-Ginet. 2000. Meaning and grammar: An introduction to semantics, 2nd edition. Cambridge: MIT Press.

Corbett, Greville G. 2000. Number. Oxford University Press.

Donabédian, Anaïd. 1993. Le pluriel en arménien moderne. Faits de Langues 2. 179-188. doi:10.3406/flang.1993.1318.

Heim, Irene. 1982. The semantics of definite and indefinite Noun Phrases: University of Massachusetts, Amherst dissertation.

Ionin, Tania \& Ora Matushansky. 2006. The composition of complex cardinals. Journal of Semantics 23. 315-360. doi:10.1093/jos/ffl006.

Kamp, Hans \& Barbara Partee. 1995. Prototype theory and compositionality. Cognition 57. 315-360. doi:10.1016/0010-0277(94)00659-9.

Kang, Beom-Mo. 1994. Plurality and other semantic aspects of common nouns in Korean. Journal of East Asian Linguistics 3(1). 1-24. doi:10.1007/BF01733148.

Kennedy, Christopher. 2007. Vagueness and grammar: The semantics of relative and absolute gradable adjectives. Linguistics and Philosophy 30(1). 1-45. doi:10.1007/s10988-006-9008-0.

Klein, Ewan. 1980. A semantics for positive and comparative deletion. Linguistics and Philosophy 4(1). 1-46. doi:10.1007/BF00351812.

Klein, Ewan. 1982. The interpretation of adjectival comparatives. Journal of Linguistics 18. 113-136. doi:10.1017/S0022226700007271. 
Cross-linguistic representations of numerals and number marking

Landman, Fred. 1989. Groups I. Linguistics and Philosophy 12(5). 559-605. doi:10.1007/BF00627774.

Landman, Fred. 2003. Predicate-argument mismatches and the adjectival theory of indefinites. In M. Coene \& Y. D'hulst (eds.), The syntax and semantics of noun phrases, 211-237. Amsterdam and Philadelphia: John Benjamins.

Link, Godehard. 1983. The logical analysis of plurals and mass terms: A latticetheoretical approach. In R. Baeuerle, C. Schwarze \& Arnim von Stechow (eds.), Meaning, use and interpretation of language, DeGruyter.

Magri, Giorgio. 2008. The sortal theory of plurals. In Atle Grønn (ed.), Proceedings of Sinn und Bedeutung SuB 12, 399-413. Oslo: Department of Literature, Area Studies and European Languages, University of Oslo.

Montague, Richard. 1974. The proper treatment of quantification in ordinary English. In Richmond H. Thomason (ed.), Formal philosophy: Selected papers of Richard Montague, 247-270. New Haven: Yale University Press.

Partee, Barbara. 1986. Noun phrase interpretation and type-shifting principles. In Jeroen Groenendijk, Dick de Jong \& Martin Stokhof (eds.), Studies in discourse representation theory and the theory of generalized quantifiers, 115-143. Dordrecht: Foris Publications.

Partee, Barbara. 1995. Lexical semantics and compositionality. In Lila Gleitman \& Mark Liberman (eds.), An invitation to cognitive science (second edition), 311-360. Cambridge: MIT Press.

Partee, Barbara. 2010. Formal semantics, lexical semantics, and compositionality: the puzzle of privative adjectives. Philologia 7. 7-19.

Schroeder, Christoph. 1999. The Turkish nominal phrase in spoken discourse. Wiesbaden: Harrassowitz Verlag.

Wilhelm, Andrea. 2006. Count and mass nouns in Dëne Su̧łiné. In Donald Baumer, David Montero \& Michael Scanlon (eds.), Proceedings of the 25th West Coast Conference on Formal Linguistics, 435-443. Sommerville, MA: Cascadilla Proceedings Project.

Wilhelm, Andrea. 2008. Bare nouns and number in Dëne Sưłiné. Natural Language Semantics 16(1). 39-68. doi:10.1007/s11050-007-9024-9.

Winter, Yoad. 1997. Choice functions and the scopal semantics of indefinites. Linguistics and Philosophy 20(4). 399-467. doi:10.1023/A:1005354323136.

Winter, Yoad. 2001. Flexibility principles in boolean semantics: the interpretation of coordination, plurality, and scope in natural language. Cambridge: MIT Press. 
A. Bale, M. Gagnon, \& H. Khanjian

\author{
Alan Bale \\ Linguistics Program, \\ Concordia University, \\ 1455 de Maisonneuve W., \\ Montréal, Québec, \\ Canada H3G 1M8 \\ alancbale@gmail.com \\ Hrayr Khanjian \\ Department of Linguistics and Philosophy, \\ Massachusetts Institute of Technology, \\ 77 Massachusetts Avenue, \\ Bldg. 32-D808 \\ Cambridge, \\ MA 02139 USA \\ khanjian@mit.edu
}

Michaël Gagnon

Department of Linguistics, University of Maryland, 1401 Mount Mary Hall, College Park, MD 20742-7505 USA

migagnon@umd.edu 